\title{
A SUPRATHRESHOLD VISIBILITY METER TO DIRECTLY ASSESS THE CONSPICUITY OF OFFICE TASKS
}

\section{Gary T. Yonemura Karen Lister}

\section{U.S. DEPARTMENT OF COMMERCE National Institute of Standards and Tochnology Natlonal Englneering Laboratory Center for Bullding Technology Bullding Environment Division Galthersburg, MD 20899}

\section{Sponsored by:} The U.S.Department of Energy Washington, DC

and

U.S. DEPARTMENT OF COMMERCE National institute of Standards and Technology Center for Bullding Technology Galthersburg, MD 20899

U.S. DEPARTMENT OF COMMERCE Robert A. Mosbacher, Secretary

Lee Mercer, Deputy Under Secrotary for Tochnology

NATIONAL INSTITUTE OF STANDARDS AND TECHNOLOGY

Raymond G. Kammer, Acting Diroctor 



\section{A SUPRATHRESHOLD VISIBILITY METER TO DIRECTLY ASSESS THE CONSPICUITY OF OFFICE TASKS}

\section{Gary T. Yonemura Karen Lister}

\author{
U.S. DEPARTMENT OF COMMERCE \\ Natlonal Instltute of Standards \\ and Technology \\ Natlonal Englneoring Laboratory \\ Center for Bullding Technology \\ Bullding Environment Divlsion \\ Galthersburg, MD 20899 \\ Sponsored by: \\ The U.S.Department of Energy \\ Washlngton, DC \\ and \\ U.S. DEPARTMENT OF COMMERCE \\ Natlonal Institute of Standards \\ and Technology \\ Center for Bullding Technology \\ Galthersburg, MD 20899
}

January 1990

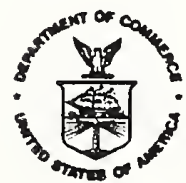

U.S. DEPARTMENT OF COMMERCE Robert A. Mosbacher, Secretary

Lee Mercer, Deputy Under Secretary for Technology NATIONAL INSTTUTE OF STANDARDS AND TECHNOLOGY

Raymond G. Kammer, Acting Dlrector 
An apparatus and methodology for evaluating the relative difficulty of visibility-related office tasks are described. The methodology differs from current evaluation techniques in that tasks are assessed in the laboratory as seen in the real world. The contrast of a reference task (5-bar grating) is varied until the conspicuity (how well the detail stands out from the background) is perceived to be equal to that of the sample task presented simultaneously. Data using typical alphanumeric materials encountered in commercial activities are presented. The investigation indicates that the apparatus and methodology give a good indication of the relative difficulty of real world sample tasks. Procedures for calibrating the task evaluators (observers) or the inclusion of a criterion correction factor in order to minimize differences in absolute values between evaluators are recommended.

Key words: conspicuity, contrast, legibility, office tasks, lighting, lighting requirements, task lighting, task performance, visibility. 


\section{PREFACE}

This report is one of a series documenting the NIST research supporting the development of measurement in lighting. The investigation reported in this document was jointly sponsored by the National Institute of Standards and Technology (NIST) and the Energy Conversion Equipment Branch of the U.S. Department of Energy through the Lawrence Berkeley Laboratory. The report is a product of the Task Lighting Criterla Project under contract DE-ACO376SF000098 to the NIST.

\section{ACKNOWLEDGEMENT}

The authors wish to acknowledge the assistance of Victor Weidner of the Radiometric Physics Division for his contributions to the design and construction of the visibility meter. 
TABLE OF CONTENTS

\section{Page}

ABSTRACT

iii

PREFACE

ACKNOWLEDGMENT

iv

1. INTRODUCTION . . . . . . . . . . . . . . . . . . . . . . . . 1

1.1 Equivalent Contrast . . . . . . . . . . . . . . 1

1.2 Purpose . . . . . . . . . . . . . . . . . 3

2. METHODOLOGY . . . . . . . . . . . . . . . . 4

2.1 Apparatus .................... . . . . . . 4

2.2 Calibration . . . . . . . . . . . . . . . . . . . 4

2.3 Contrast Measurements . . . . . . . . . . . . . 7

2.4 Stimulus...................... . . . . 7

2.5 Procedure ................... . . . . . . . 12

3. RESULTS . . . . . . . . . . . . . . . . . . . . . . 13

4. DISCUSSION . . . . . . . . . . . . . . . . . . . . . 19

5. REFERENCES . . . . . . . . . . . . . . . . . . . . 24 
Figure 1. A schematic representation of the conspicuity meter. IS $_{1-5}$ are integrating spheres, L the light source, $A_{1-3}$ are diamond shaped apertures with area variable, RT is the reference target, TT the test target, LBC a LummerBrodhun cube and $\mathrm{E}$ the eye . . . . . . . . . . . .

Figure 2. Luminance as a function of dial setting for reference detail. . . . . . . . . . . . . . . . .

Figure 3. Rate of luminance change for detail and background of reference target for equal changes in scale settings. The dashed line represents the ideal condition where equal scale changes result in the same luminance change for reference detail and background . . . . . . . . . .

Figure 4. The stimulus as seen by the observer. RT is the reference target and TT the test target. Depictions of the gratings are only symbolic and not to scale. See text for actual grating dimensions... . . . . . . . . . . . .

Figure 5. Real world test targets used in this study. The targets were not photocopies, but originals. For instance, sample 4 was handwritten in pencil. Sample 3 was actual computerprint with green lines and blue prints........ .

Figure 6. Stimulus as seen by the observer, where the test and reference targets are similar in form, size and sharpness. Depictions of the gratings are only symbolic and not to scale. See text for actual grating dimensions..... .

Figure 7. Mean matching contrast when the test target is similar in form, size and sharpness to the reference target, for three trials in successive order. Data for five subjects; square (VW), open triangle (KL), filled triangle (TH), filled circle (GY) and open circle (BC), are shown. One subject (filled circle) completed two trials . . . . . . . .

Figure 8. Standard deviation of matching contrast where the test target is similar in form, size and sharpness to the reference target, for three successive trials. Data for five subjects; square (VW), open triangle (KL) filled circle (GY) and open circle (BC), are shown. One subject (filled circle) completed two trials).............

Figure 9. Mean matching contrasts for six real world tasks for five subjects. Symbols: triangle (TH), circle (VW) and square $(B C)$. The two subjects who made matches for all six tasks are given by the dashed (KL) and solid (GY) lines . . . 
Figure 10. Standard deviations of matching contrast for six real world tasks for two subjects, solid line (GY) and dashed line $(\mathrm{KL})$. . . . . . . . . . . . . . . .

Figure 11. Mean matching contrasts, corrected for deviation of the obtained from the expected contrast, when the reference and test targets were similar, for two subjects (solid line, GY and dashed line, KL) . . . . . . . . . . .

Figure 12. (a) Standard deviation of matching contrast for target number 1 on six successive days for two subjects (solid line, GY and dashed line, KL)

(b) Mean matching contrast for target number 1 on six successive days for two subjects (solid line, GY and dashed line, KL) . . . . . . . . . . . . .

\section{LIST OF TABLES}

Table 1. Matching contrast for real world tasks matched against 5-bar reference target for equal conspicuity. Each trial is the average of 28 runs. Sample real world targets are shown in figure 5. . . . . . . . . . . . . . . . . . . . 

Conspicuity, as used in this report, is defined as: "how well the detail stands out from the background." The term visibility, broadly defined as: "the quality, state or degree of being capable of being seen," will be used interchangeably with conspicuity. This is intended to give visibility a more specific definition and convey the idea that we are primarily concerned with "goodness of seeing," no matter what popular term is used. For the same reason, legibility, defined as: "ease of reading," will be used interchangeably with conspicuity, when we are referring to goodness of seeing alphanumerics.

In a typical office, tasks may range from highly visible to barely visible. Even when restricted to two-dimensional tasks, the legibility of written material may range from highly legible typewritten original or printed copies to barely legible duplicated materials. Generally, the higher the contrast, the greater the legibility. Also, as detail size increases, legibility increases. Additional ways in which office tasks can differ in legibility, are: form (type font), sharpness (edge gradient), lightness (reflectance), color (chromaticity), gloss (specularity) and texture (diffusion).

Most of the variables listed above have been utilized in evaluating the legibility of tasks, but have been investigated using a traditional parametric approach examining a single variable, with all others kept constant. This approach is not appropriate for many studies of visibility and legibility. For example, two letters with the same physical contrast, but differing in size will be perceived to be different in contrast or conspicuity. Tasks with the same physical contrast and apparent size, but differing in the amount of blur, will also be perceived to have different contrasts. These interactive effects hold for the other variables listed earlier. Studies in which two variables are varied simultaneously indicate a significant complex interaction between the variables, where the functions of the single variables could not be cascaded (treated as products of the functions). For this reason, although analytic expressions for visibility are available for some of the variables expressed as a single or two variable function, the legiblility of real world tasks that differ in many ways must be evaluated as generic task types, rather than by parametric means. Future research may result in a single analytic expression that will include most of the variables. A nonanalytic procedure for handling this problem of a single scale for tasks that may differ in several visual variables, where the functions cannot be cascaded, is the concept of "equivalent contrast."

\subsection{EQUIVALENT CONTRAST}

The Illuminating Engineering Society of North America, IESNA, defines equivalent contrast, $C_{e q}$, as: "A numerical description of the relative visibility of a task. It is the contrast of the standard reference visibility task giving the same visibility as that of a task whose contrast has been reduced to threshold when the background luminances are the same." [1] 
The term "visibility" in the preceding definition is subject to various interpretations. With an interpretation that is currently widely accepted, equivalent contrast has been quantitatively defined [2] as:

$$
\begin{aligned}
c_{e q} & \left.=\left[c_{t} / \bar{c}_{t}\right) /\left(c_{r} / \bar{c}_{r}\right)\right] c_{r} \\
& =i_{t}\left(\bar{c}_{r} / \bar{c}_{t}\right),
\end{aligned}
$$

where $C$ is contrast and $C$ is threshold contrast. The subscript " $t$ " is test and " $r$ " is reference. With background luminance kept constant, luminance contrast is varied until the task is at threshold. Visibility of the test and reference tasks is said to be equal, no matter how they differ physically, since they are both at threshold. Equivalent contrast is used as a measure of visibility for tasks differing in terms of several variables. Although the tasks may differ from one another with respect to one or more variables, the contrast of the test task divided by the threshold contrast for the test task, $\left(C_{t} / \bar{C}_{t}\right)$, relative to that for the reference task, $\left(C_{r} / \bar{C}_{r}\right)$, is taken as the index of relacive visibilicy. From Eq. 2, we see that equivalent contrast is equal to the ratio of the threshold contrast for reference and test tasks times the objective contrast of the reference task. By this interpretation equivalent contrast is, "a measure of the visual difficulty of a task, representing the luminance contrast of the visibility reference task having equal visibility at the same level of task luminance." [2]

A more intuitive explanation for $\mathrm{Eq} .2$ can be seen by rewriting it in the form

$$
c_{e q} / \bar{c}_{r}=c_{t} / \bar{c}_{t}
$$

The underlying assumption of this approach--really a definition--is that two suprathreshold objects are equally "visible" if their contrasts must be reduced by the same factor to bring the objects to threshold.

Most office tasks are not performed at visual threshold levels, i.e., where visibility is so poor that the worker can barely determine that something is there (detection threshold), or the legibility is so bad that the observer can barely recognize that the targets are letters (recognition threshold), or the observer can barely distinguish between an $E$ and an $F$ (identification threshold). Instead the tasks are generally significantly above threshold (suprathreshold) levels, the difference being "goodness of seeing:" some tasks are easier to see than others. Tasks at or near threshold levels are generally considered to be intolerable and sustained work performance will therefore suffer.

Since most real world office tasks are at suprathreshold levels, a more valid procedure for evaluating the visibility of the tasks than artificially bringing them down to the visibility threshold and then extrapolating to suprathreshold levels, is to evaluate them as they are seen in the real world. The general problems of extrapolation from threshold laboratory 
measures to tasks performed at suprathreshold levels are discussed in reference [3], which also describes the difficulties encountered with measures of work performance, e.g., reading speed or productivity.

In a direct evaluation of unattenuated real world tasks, the relation between the visual difficulty of a task, $C_{e q}$, and the reference task conspicuity, $C_{r}$, will simply be:

$$
\mathrm{C}_{\mathrm{eq}}=\mathrm{C}_{\mathrm{r}} \text {, }
$$

the subscripts being the same at that for Eq. 1. Equivalent contrast in this sense--the definition to be used in this report--is the contrast of the reference task that is perceived to be equal in conspicuity to the unattenuated test target. This concept will be described in greater detail under procedure (2.5).

\subsection{PURPOSE}

The purpose of this study is to develop an instrument and a methodology to evaluate the "goodness of seeing" of office tasks, as they are encountered in the real world. The requirement is that the visibility of the real world test task not be altered, e.g., brought down to threshold. This can be accomplished by presenting the reference and test tasks simultaneously, with the reference task being varied until they both appear equal in conspicuity (how well the detail stands out from the background). Conspicuity in this sense is presumed to be equivalent to perceived contrast. 


\subsection{APPARATUS}

A schematic diagram of the suprathreshold conspicuity meter is shown in figure 1. The L's are $45 \mathrm{~W}$ tungsten halogen lamps connected in series, with current kept constant at $6.0 \mathrm{~A}$ (rated $6.6 \mathrm{~A}$ ). The lamps are mounted in integrating spheres IS $_{5}$ and IS $_{4}$, which are connected by short tubes with integrating spheres $I_{3}$ and $I_{1}-2$, respectively. The integrating spheres, IS, are press-coated with polytetrafluorethylene (Halon). The luminances of the reference and test targets are controlled by variable diamond-shaped apertures $A_{1}-3$. Light reflected off the walls of $I_{3}$ illuminates the test target, TT, i.e., the test target is always evaluated under spherical illumination. The light reflected from TT is transmitted through the LummerBrodhun Cube, $L B C$, to the eye, except for the central portion of the target which is reflected at the LBC. The luminance of the reference target, RT, background which includes the light portion of the five-bar pattern is controlled by $A_{2}$. Light reflected off the walls of $\mathrm{IS}_{2}$ and incident on the RT is reflected from the central area of the LBC to the eye. Light reflected off the walls of IS $_{1}$ escapes through thin slits etched in the reference target and is reflected to the eye by LBC. Aperture $A_{1}$ controls the luminance of the dark lines (i.e., slits) in the five-bar patterns. An adjustable chin and forehead rest is located at $E$. The viewing is monocular. The reference and test targets will be discussed in greater detail in section 2.4 .

\subsection{CALIBRATION}

There are three luminances that must be known and controlled in making conspicuity evaluations: reference background $\left(L_{r b}\right)$, reference detail ( $L_{r d}$ ) and test background $\left(L_{t b}\right)$. Two of these, the reference and test backgrounds, are kept constant at $120 \mathrm{~cd} / \mathrm{m}^{2}$ (35 fL). The background luminance of 120 $\mathrm{cd} / \mathrm{m}^{2}$ was chosen as being the best approximation of an optimum luminance value for suprathreshold viewing [3]. The reference task contrast is varied by the Iuminance of the detail.

The background luminances are obtained by visual brightness matching. The luminance of the reference detail is set at $120 \mathrm{~cd} / \mathrm{m}^{2}$ (35 fL). The aperture $A_{2}$ controlling the flux entering $I_{2}$ is varied until the reference detail disappears, i.e., reference background luminance is varied until it is equal in brightness to the detail. At this time the observer sees a homogeneously illuminated disc in the center of the field, surrounded by the given test task to be evaluated. The test background of $120 \mathrm{~cd} / \mathrm{m}^{2}$ is obtained by a similar procedure. A3, controlling the flux entering $\mathrm{IS}_{3}$, is varied until the inner circle disappears. In many cases because of differences in the spectral reflectances between the test and reference tasks, the inner disc cannot be made to disappear. In these cases the observer varfes $A_{3}$ so that the border separating the two backgrounds is at a minimum contrast, or makes brightness matches between the two fields.

The only luminance that requires a complete calibration of luminance as a function of aperture scale setting is that for the reference target detail. 


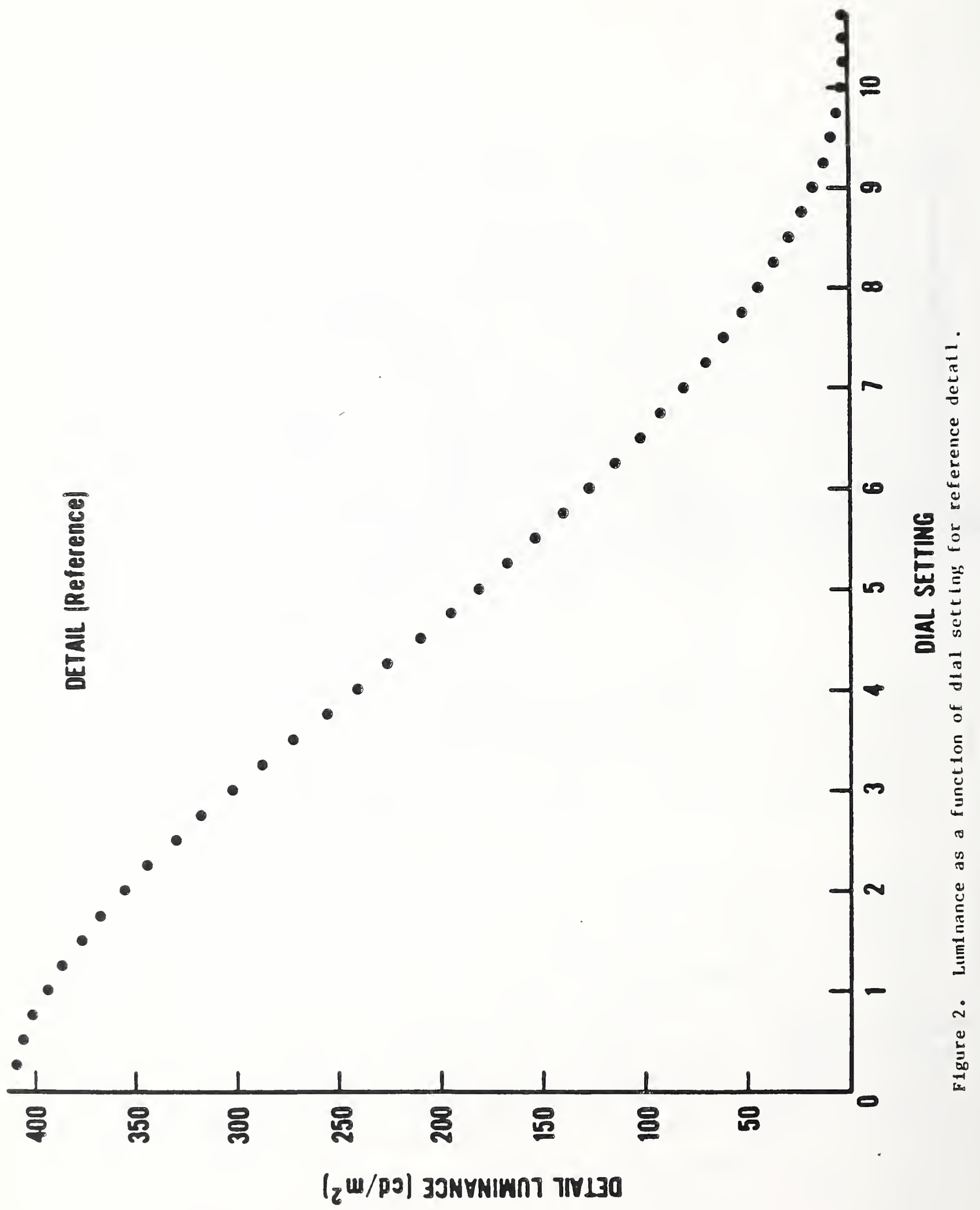


Figure 2 presents a plot of luminance vs. scale setting for the reference task detail. The expectation is that $L$ should be a linear function of the scale readings, since it in turn is linearly related to area of the aperture. However, the rate of change of background and detail luminances are not the same. See figure 3. A similar rate of change would require that only one of the scale settings be completely calibrated, but for this series of studies, where background luminances are obtained by visual matches against a single calibrated scale, this lack of agreement is not important, as visual brightness matching is used to set two of the luminances from the third.

\subsection{CONTRAST MEASUREMENTS}

The most critical measure in this study is the contrast between the reference background luminance $\left(L_{b}\right)$ and detail luminance $\left(L_{d}\right)$. Contrast is defined as:

$$
C=\left(L_{b}-L_{d}\right) / L_{b}
$$

and since the light is coming from a single source, any deviation in the light source output will alter all luminances by the same proportion and will not affect the ratio $C$. It is for this reason that the same source is used to illuminate $I_{1}$ and $I_{2}$. Contrast is varied by varying the luminance of the reference detail.

Light entering the "background sphere" $\left(I S_{2}\right)$ through the slits of the reference detail makes a contribution to reference background luminance which is variable, but is always less than one percent of the measured value. No correction has been made to the data for this.

\subsection{STIMULUS}

Figure 4 presents the subject's view of one stimulus pattern. The inner circle is the five-bar reference task and the outer annulus, the test task. The reference and test targets are observed at a $25^{\circ}$ viewing angle from the normal. The reference task is a nickel disc $50.8 \mathrm{~mm}(2.00 \mathrm{in.})$ in diameter in which slots $0.40 \mathrm{~mm}(0.016 \mathrm{in.})$ wide by $6.35 \mathrm{~mm}(0.25 \mathrm{in}$.) long have been etched out by the electroforming process. The spaces between the slots are $0.215 \mathrm{~mm}(0.0085 \mathrm{in.})$. At the viewing distance of $40.64 \mathrm{~cm}$ (16 in.) the dark bars (slots) subtend a visual angle of $3.38 \mathrm{~min}$ in width by 53.7 min in length. The spaces between bars subtend $1.82 \mathrm{~min}$. The six real world test samples, 3 in. in diameter, are shown in figure 5. Although imperfections in the photoreproductive process lead to inaccuracies in the contrasts shown, in comparison to those of the actual tasks used in the study, the reproduction does give an idea of the relative differences between the stimuli.

Tests were also run with test targets similar in form (5-bar) and sharpness (edge gradient) to the reference target. See figure 6 . The test target dark bars were $0.260 \mathrm{~mm}(0.010 \mathrm{in.})$ wide and the spaces between the bars were $0.370 \mathrm{~mm}(0.015 \mathrm{in.})$, subtending 2.20 and $3.13 \mathrm{~min}$, respectively. The dark bars were $7.50 \mathrm{~mm}(0.295 \mathrm{in.})$ long and subtended $1.06^{\circ}$ at the viewing distance of $406.4 \mathrm{~mm}$ (16 in.). The reference target dimensions were described earlier. It should be noted that the proportion of bar width to space width for this test target was quite different from the proportion 


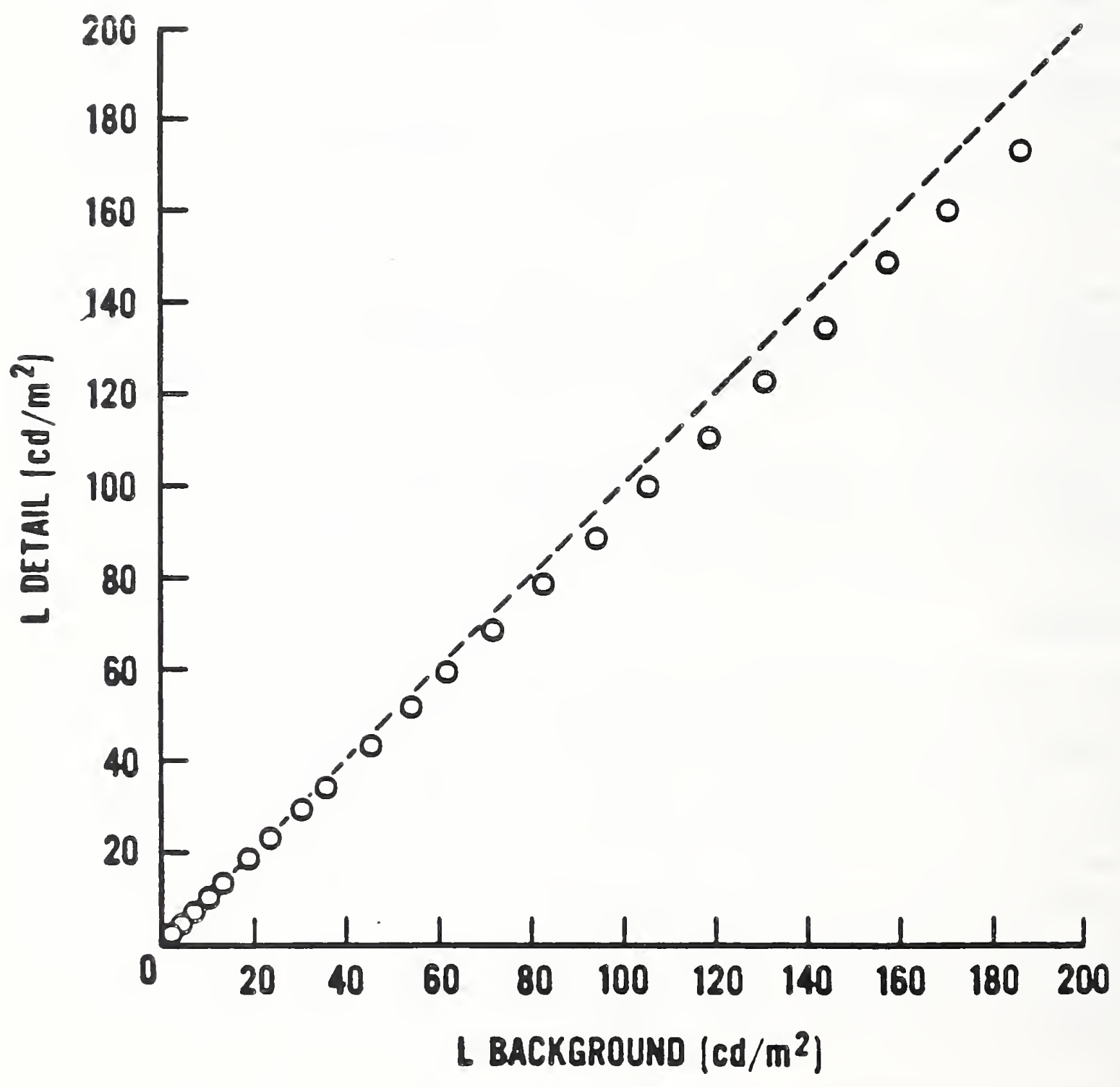

Figure 3. Rate of luminance change for detail and background of reference target for equal changes in scale setrings. The dashed line represents the ideal condition where equal scale changes results in the same luminance change for reference detail and background. 


\section{STIMULUS FOR OBSERVER}

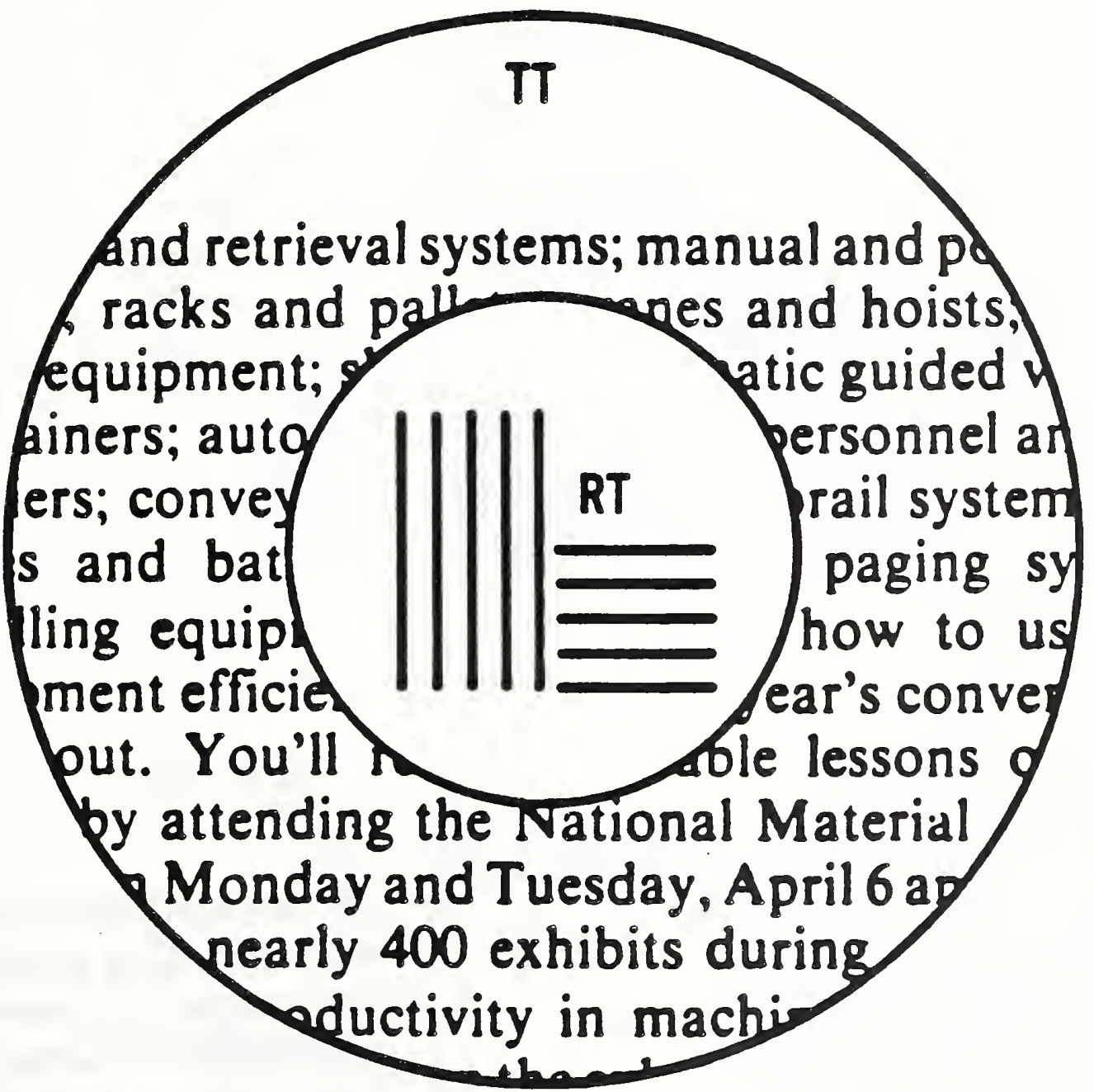

Pigure 4. The stimulus as seen by the observer. RT is the reference target and TT the test target. Depictions of the gratings are only symbolic and not to scale. See text for actual grating dimensions. 


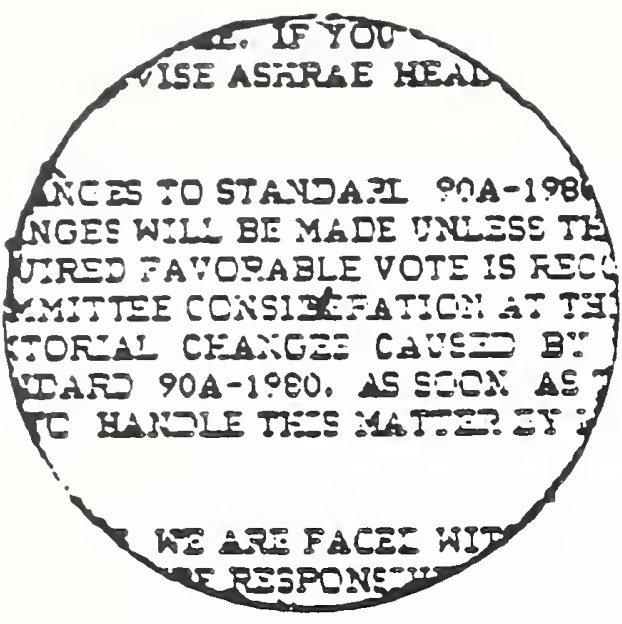

1
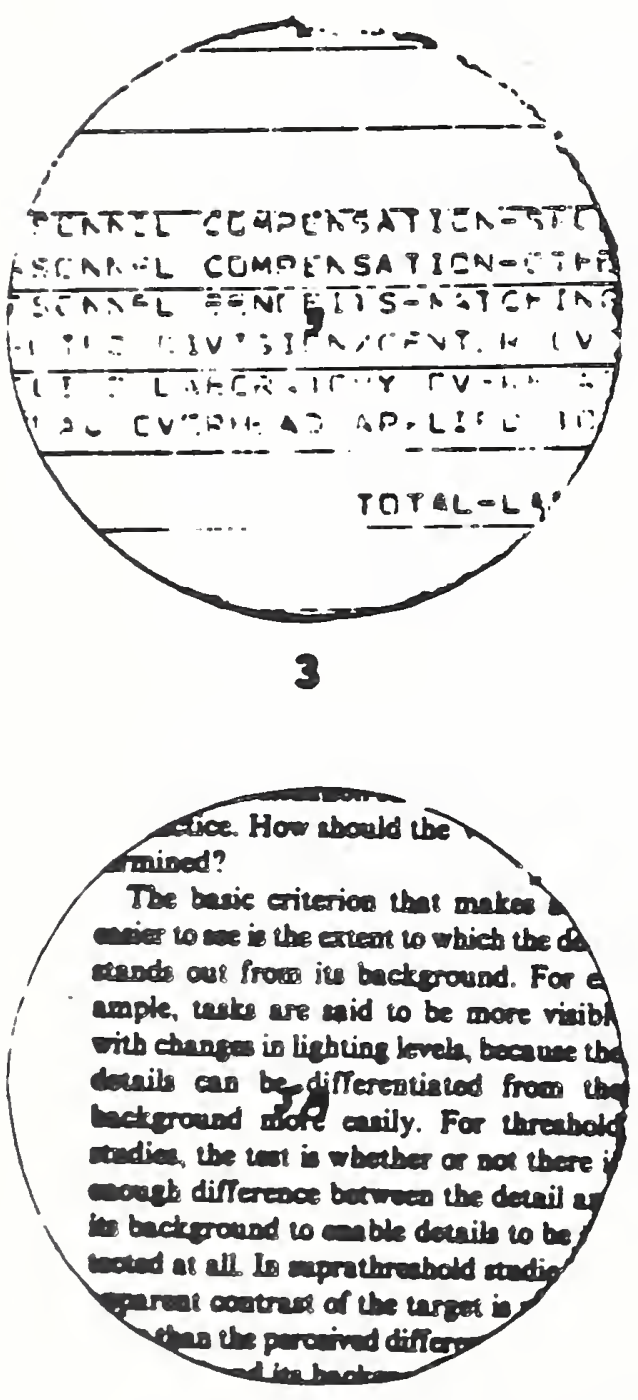

SA
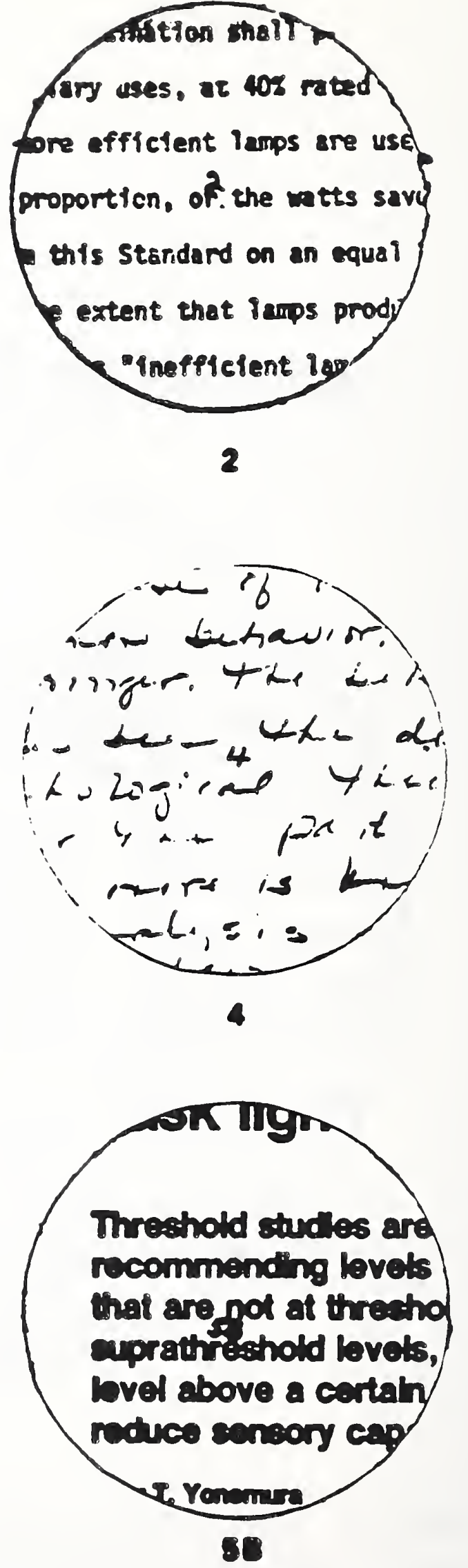

Figure 5. Real world test targets used in this study. The targets used were not photocopies, but originals. For instance, sample 4 was handwritten in pencil. Sample 3 was actual computer-print with green IInes and blue prints. 


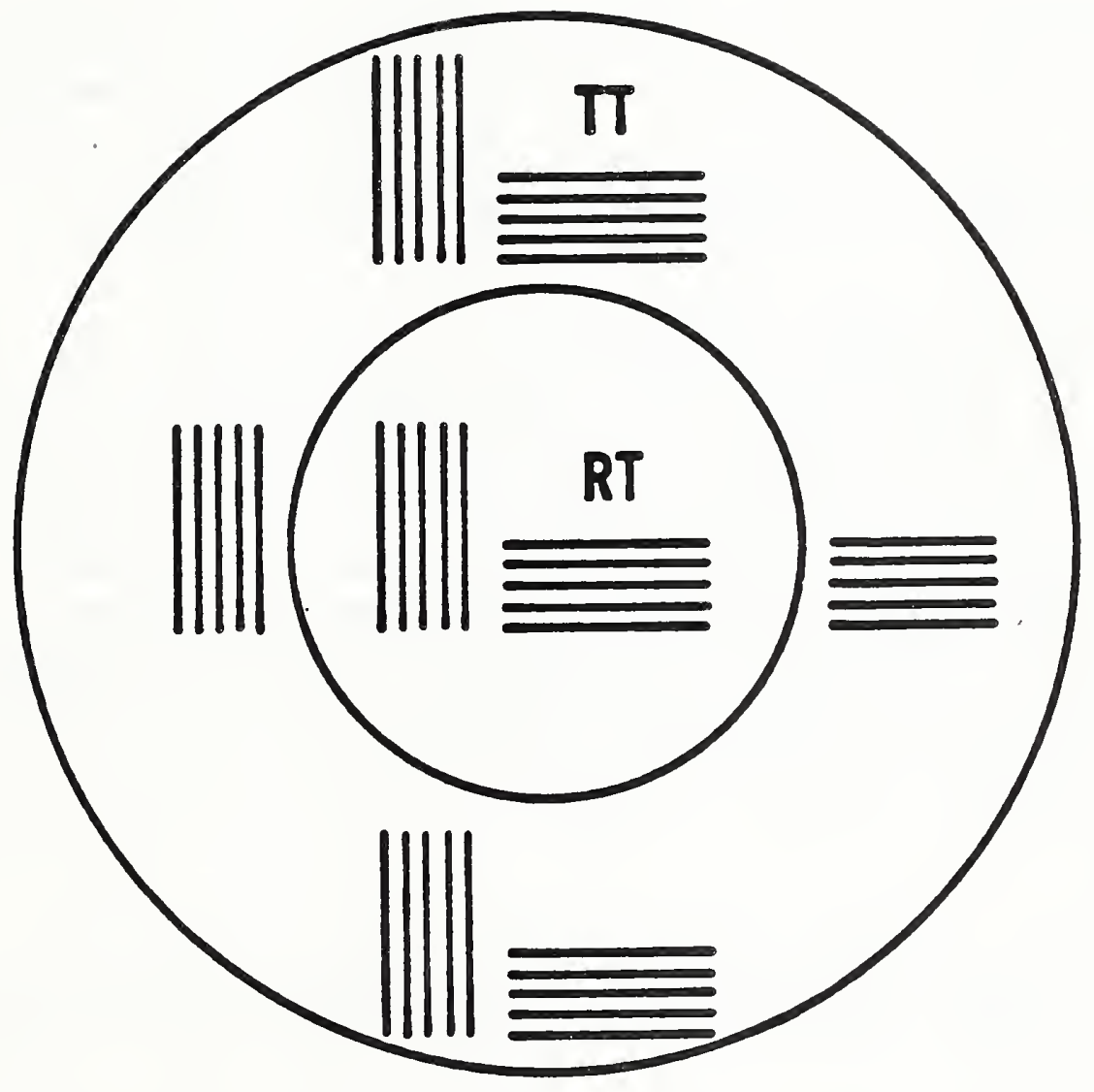

Figure 6. Stimulus as seen by the observer, where the test and reference targets are similar in form, size and sharpness. Depictions of the gratings are only symbolic and not to scale. See text for actual grating dimensions. 
characterizing the reference target. One observer (KL) used a smaller fivebar target. The dark bar width was $1.67 \mathrm{~min}$., the length $0.85^{\circ}$, and the spaces between bars subtended $2.60 \mathrm{~min}$.

\subsection{PROCEDURE}

The reference detail luminance is set at $120 \mathrm{~cm} / \mathrm{m}^{2}$ (35 fL), the background luminance under which conspicuity evaluations are to be made. The luminance of the reference background is varied until the lines in the five-bar target disappear. The reference background luminance is now approximarely 120 $\mathrm{cd} / \mathrm{m}^{2}$.

With the given test sample to be evaluated in place, the luminance of the test background is varied until the border separating the reference and test backgrounds disappears or is at a minimum, brightness matches being allowed, if preferred. The reference and test background are now approximately 120 $\mathrm{cd} / \mathrm{m}^{2}$. The setting of reference and test background luminances were based on the settings of two observers, whose values were very close. The other observers used these same values for the background luminances.

The experimenter changes the luminance of the reference detail so that the conspicuity of the reference detail (how well the lines stand out from the background) is significantly different from equality with the conspicuity of the task detail. The subject adjusts the luminance of the detail, changing fixation from reference to test target, if necessary. The subject is asked to use a specific portion of the test stimulus rather than employ an overall assessment of the whole target, and to use the same portion on subsequent runs. The subjects are instructed to use either the vertical or horizontal bar patterns for a given trial, and keep the same bar orientation during the entire trial. The observer is encouraged to bracket adjustments, i.e., proceed from less-equal-more conspicuous, more-equal-less conspicuous, and so forth until he feels confident about his response. However, to deal with a small but consistent backlash observed during calibration the observer is told to complete the run with the adjustment direction requiring an increase in luminance.

This procedure (run) was repeated 28 times for each trial, which took approximately $30 \mathrm{~min}$. to complete. The experimenter set the reference target so that it was more conspicuous or less conspicuous than the test target on alternate runs.

The observers had experience in making laboratory observations, but except for one subject GY, were not familiar with the use of this equipment or set of targets. The observers were shown how the instrument works and how equal conspicuity matches are made, but were not given practice trials. The observers were asked to use whatever refractive corrections (eyeglasses) they normally use for near field viewing. 


\section{RESULTS}

Runs were made with test targets similar in qualitative form (5-bar) and sharpness (edge gradient) to the reference target. See figure 6 . The reference task contrast perceived to be equal in conspicuity to the test task when the test task was also a 5-bar target is shown in figure 7 . The conspicuity matches are for matches obtained on three different days for each subject, except one who only ran on two days. The trials are in successive order, but not necessarily on consecutive days. There are indications of a constant difference between observers in their matching contrasts. The mean values for two observers, 0.795 (BC) and 0.799 (GY) are nearly equal to the physical contrast of the reference task, 0.806 . The other three observers consistently fall above or below the physical contrast of the reference target. The grand mean, over all trials and subjects, is 0.805 , against the reference task physical contrast of 0.806 .

Standard deviations for the same set of data are graphed in figure 8 . Values for three of the observers indicate an improvement in matching consistency between trial 1 and trial 2. Values for subject GY, who had the most experience with the task, show a reversal. Values for one subject indicate little difference in the variability of settings among the three days.

The results for the six real world office tasks are presented in figure 9. Two observers made conspicuity matches for all six tasks. Mean values for matching contrast are connected by solid (GY) and dashed (KL) lines without symbols. Their results are also presented in table 1 which includes a breakdown by trials. The data for three additional observers who made matches only for some of the tasks, generally a single trial, are also shown in figure 9 as open circles, squares and triangles. In plotting figure 9 , the target with the highest matching contrast for KL, 5B, was arbitrarily placed first, the next highest, 5A second, and so forth. The data points for GY indicate good agreement with the rankings of $\mathrm{KL}$, but the absolute levels are consistently higher for $\mathrm{KL}$.

The standard deviations associated with the six real world targets for two observers are presented in figure 10. The target ordering on the abscissa is the same as that for figure 9, from high to low matching contrasts. Subject $\mathrm{KL}$ (dashed line) displays consistently less variability and more orderliness than GY (solid line). As matching contrast decreases, the standard deviation increases, remains flat, then increases again for the lowest matching contrast. The data for $G Y$ indicate a similar trend except for target number 3 , but data from additional subjects will be required to establish the form of the function. 


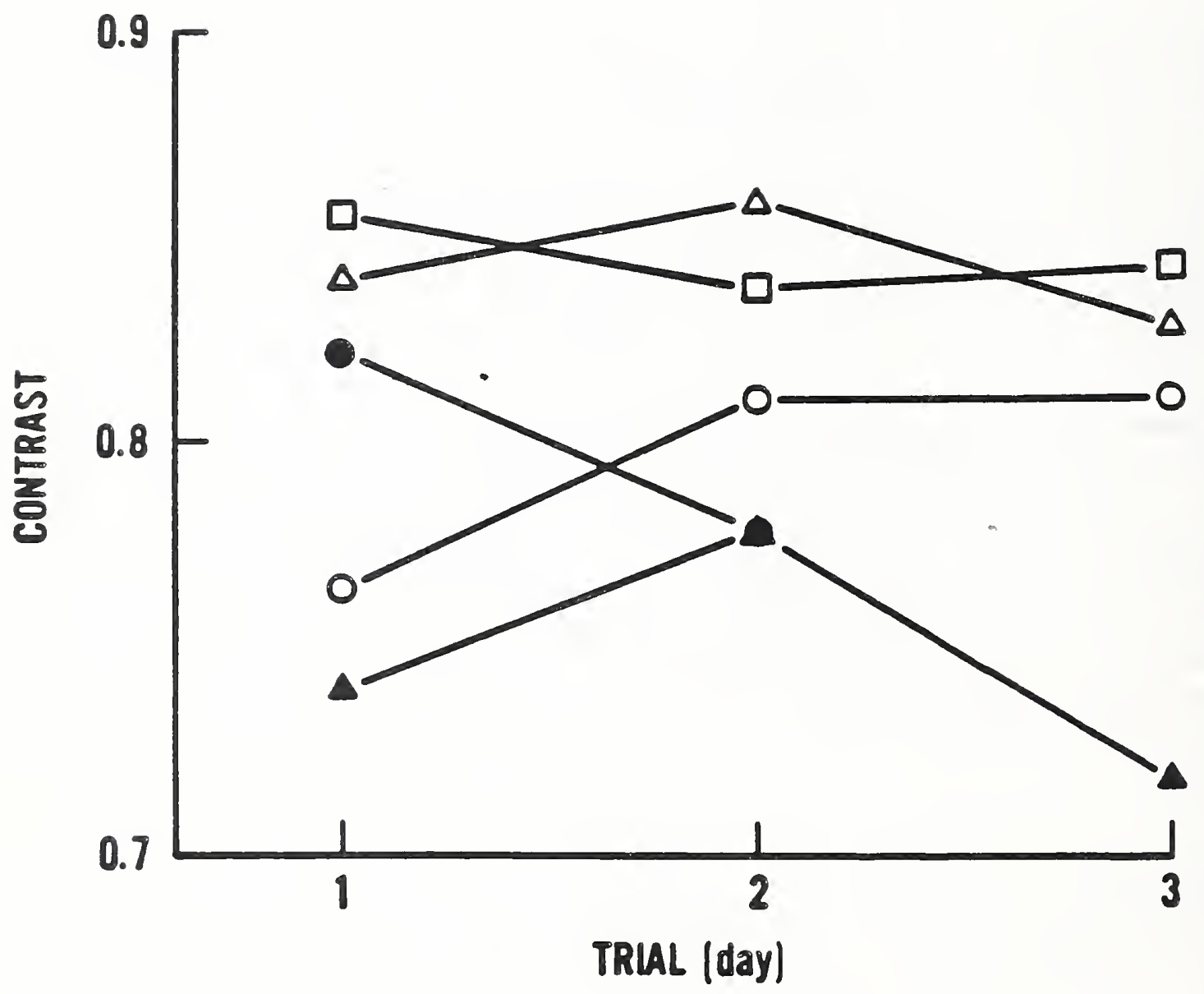

Figure 7. Mean matching contrast when the test target is similar in form, size and sharpness to the reference target, for three trails in successive order. Data for five subjects; square (VW), open triangle (KL), filled triangle (TH), filled circle (GY) and open circle (BC), are shown. One subject (filled circle) completed two trials. 


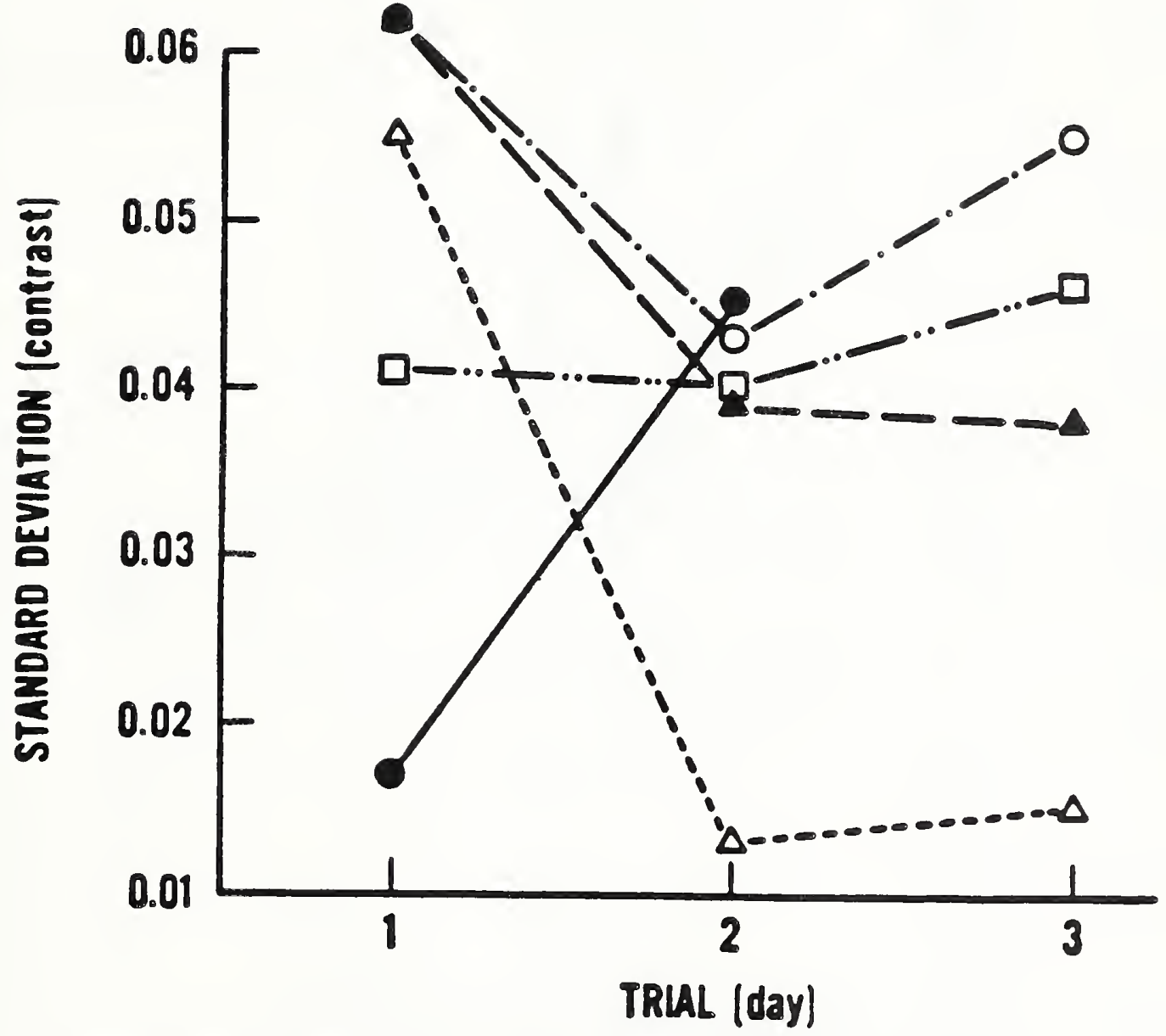

Pigure 8. Standard deviation of matching contrast where the test target is similar in form, size and sharpness to the reference target, for three successive trials. Data for five subjects; square (VW), open triangle (KL) filled circle (GY) and open circle (BC), are shown. One subject (filled circle) completed two trials. 


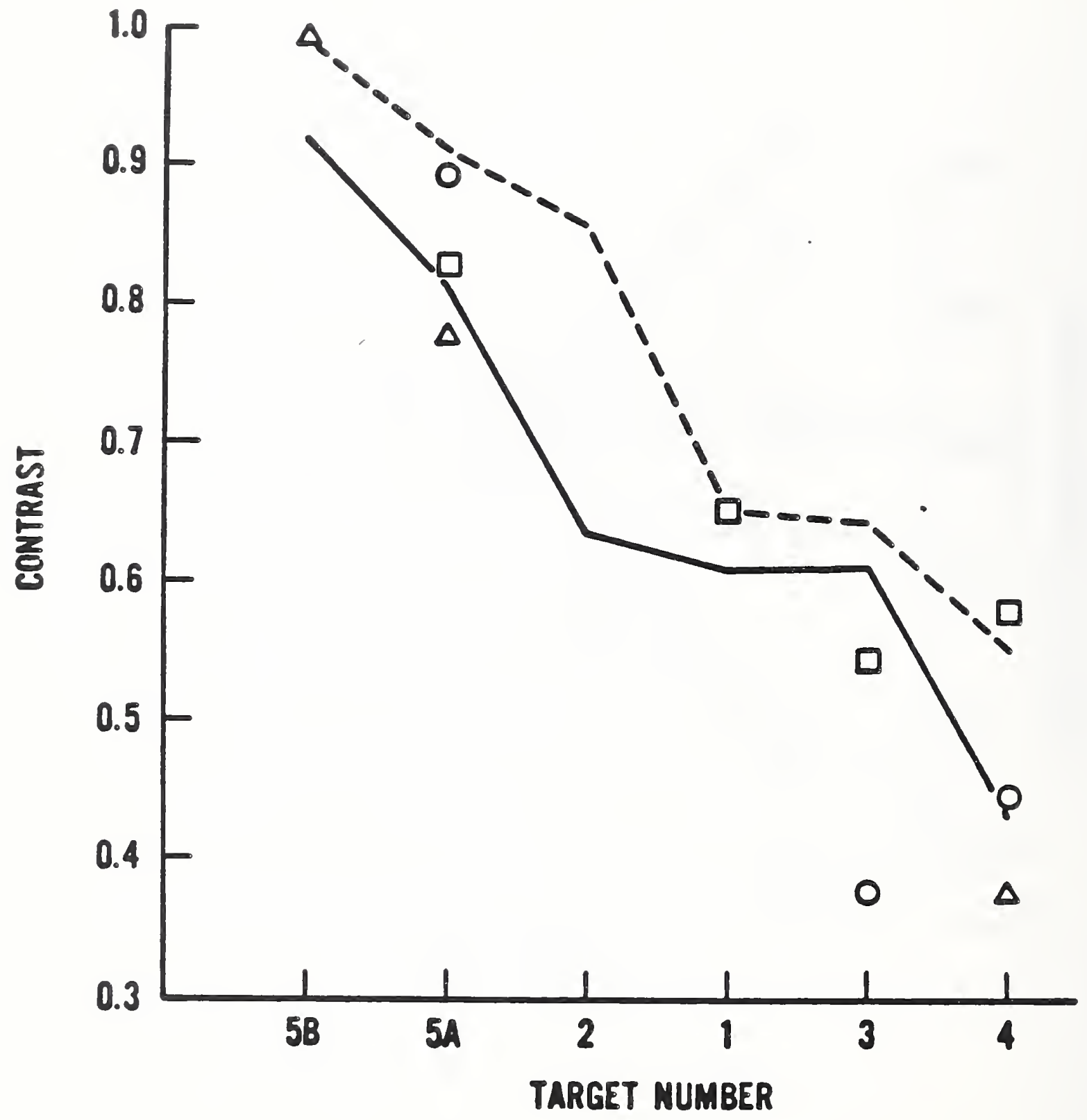

F1gure 9. Mean matching contrasts for six real world tasks for five subjects. Symbols: triangle (TH), circle (VW) and square (BC). The two subjects who made matches for all six tasks are given by the dashed $(\mathrm{KL})$ and solid (GY) Iines. 


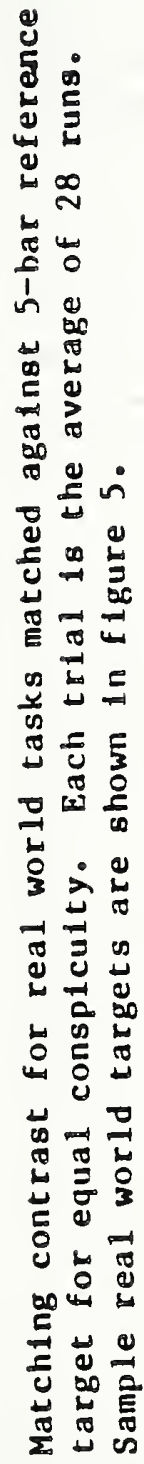

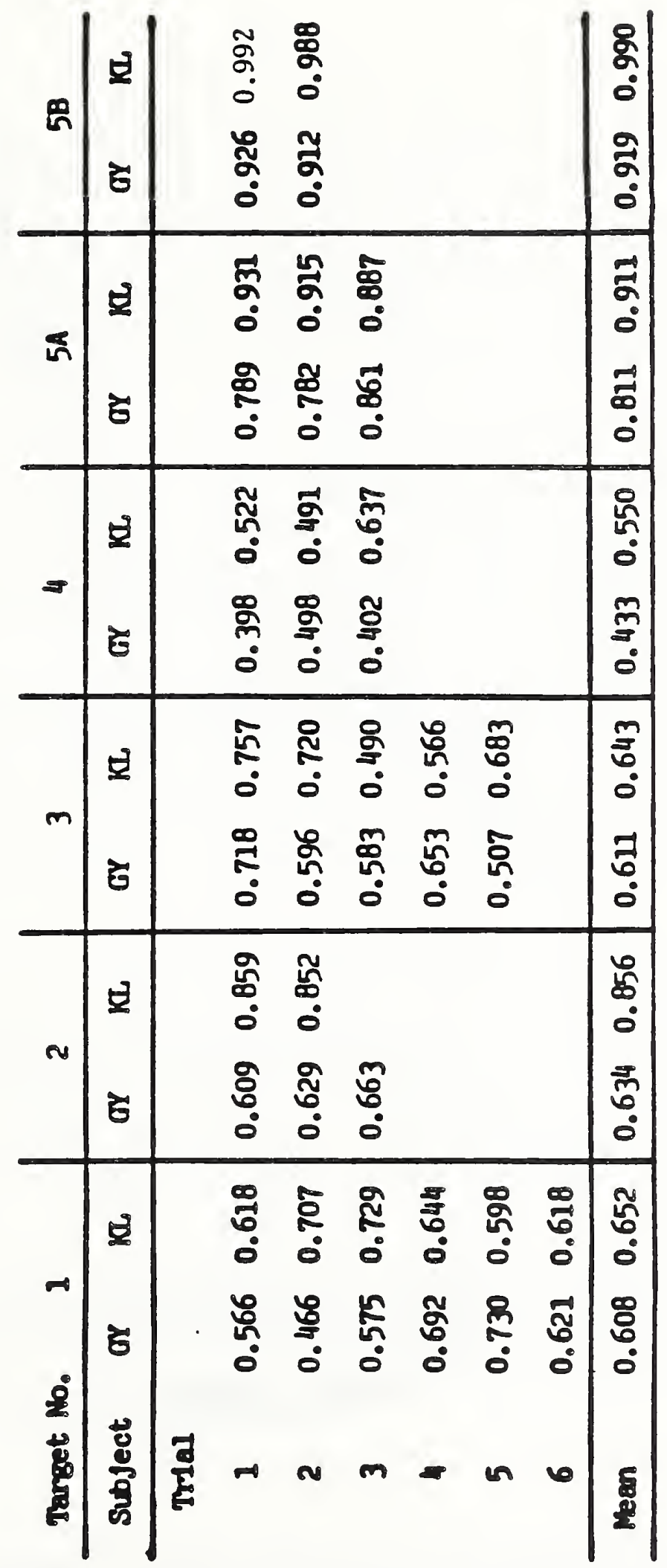




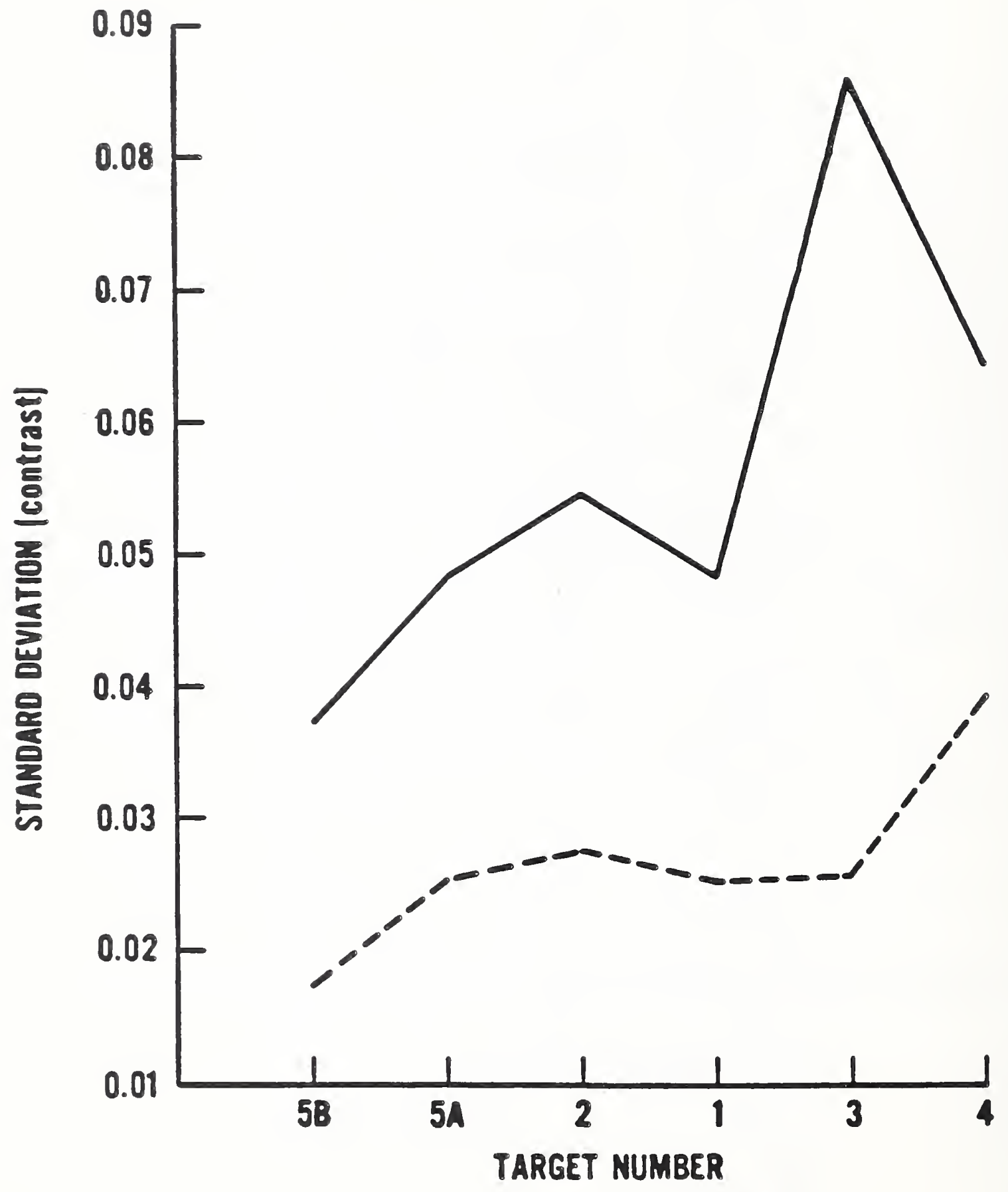

Figure 10. Standard deviations of matching contrast for six real world tasks for two subjects, solid line (GY) and dashed line (KL). 
The rankings of the six real world stimuli by two observers are similar, but there is a consistent difference in absolute matching contrast values. Since these matching contrast values ultimately will have numerical significance when samples evaluated by different observers are compared, as well as when different installations are examined, these absolute differences in matching contrast should be as small as possible, or ideally, nonexistent. That is, matching contrasts obtained with a common task at installation $A$ and $B$, or by observers $C$ and $D$ at the same installation, should be comparable. The constant difference observed in this study may be a function of criteria differences, i.e., each subject's criterion for conspicuity.

The results for the trials where the test target was a 5-bar target, similar to the reference 5-bar target, also indicate the existence of this constant difference in absolute values. The grand mean for the 5-bar target, for all subjects and all trials, was very close to the physical contrast of the test target. Subject KI's values, for all trials, are consistently higher than the obtained grand mean and physical contrast. See figure 7. KL also had consistently higher values than GY for the real world tasks. See figure 9.

Whatever the underlying cause of this constant difference in contrast values, it may be helpful to have observers calibrated so that their matching contrasts agree with known values of a common test task, which in turn means agreement with each other. When reference and test tasks are similar, the expectation is that the matching contrast should be close to the physical contrast of the test target. The following training may aid in minimizing differences between observers.

The observer is asked to make conspicuity matches between two targets similar in all respects, e.g., form, size, and edge gradient. The contrast of this calibration test target is known and since the reference and test targets are similar, the resulting matching contrast for the reference task should ideally be the measured contrast of the test target. The subject, having made a match, compares his conspicuity match against the measured contrast. On the next run, using the results of the previous run as a guide, he makes another conspicuity match intentionally biasing his response to agree with the measured value. This process is continued until the observer is consistently able to reproduce the physical contrast of the test stimulus.

An alternative procedure is suggested by the results presented in figure 7 . The assumption is that constant differences obtained when reference and test targets are similar, will also manifest themselves proportionately when other samples are measured. The deviation between physical and matching contrast can be treated as a constant error, and used as a correction factor. Then Eq. (3) for equivalent contrast becomes:

$$
c_{e q}=c_{r}\left(c_{t} / c_{r t}\right)
$$

where $C_{t}$ is the physical contrast and $C_{r t}$ is the matching contrast for a 5bar test target similar to the reference target. Obviously, the correction 


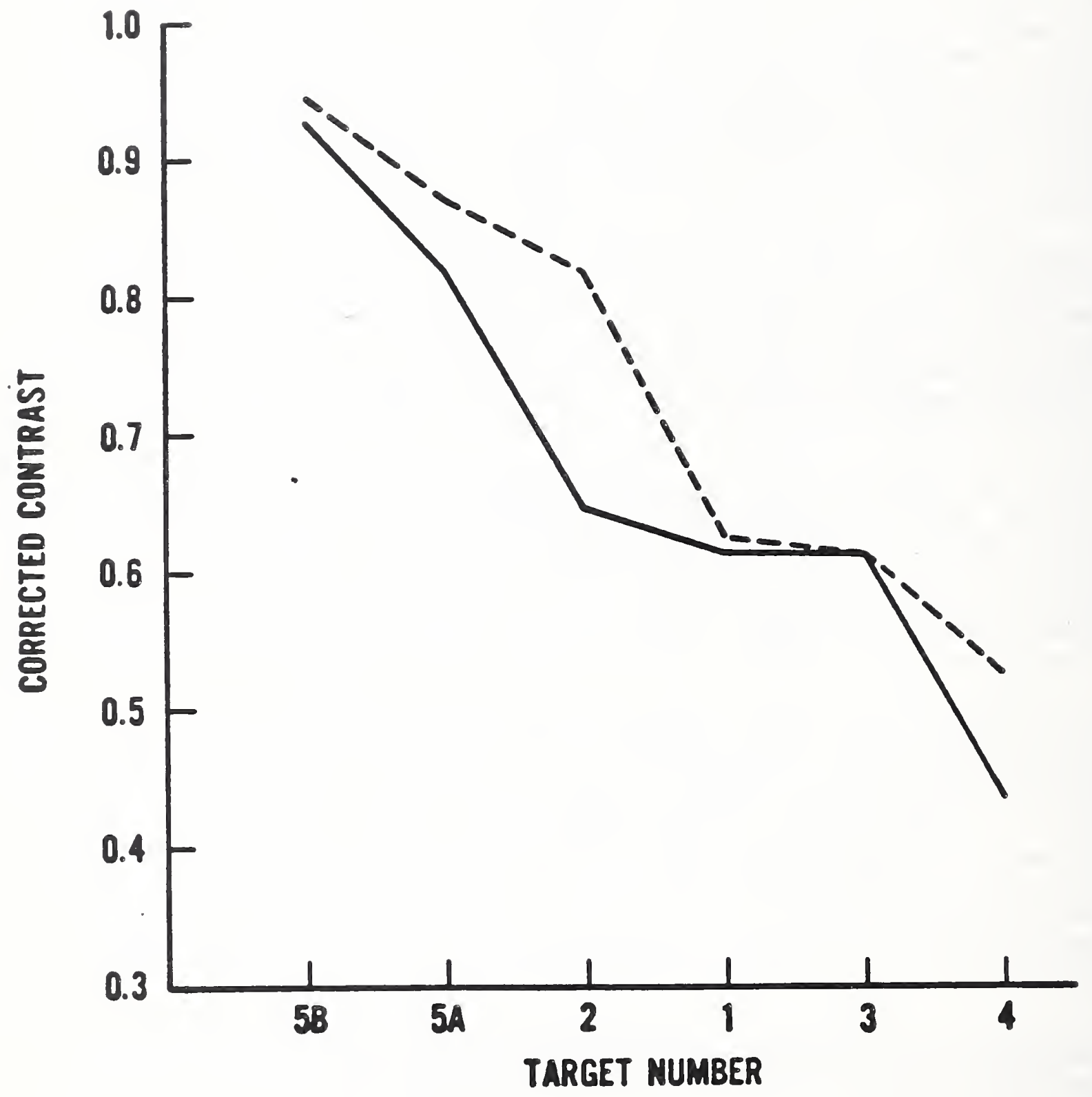

R1gure 11. Mean matching contrasts, corrected for deviation of the obtained from the expected contrast, when the reference and test targets were simllar, for two subjects (solid line, GY and dashed line, $\mathrm{KL})$. 

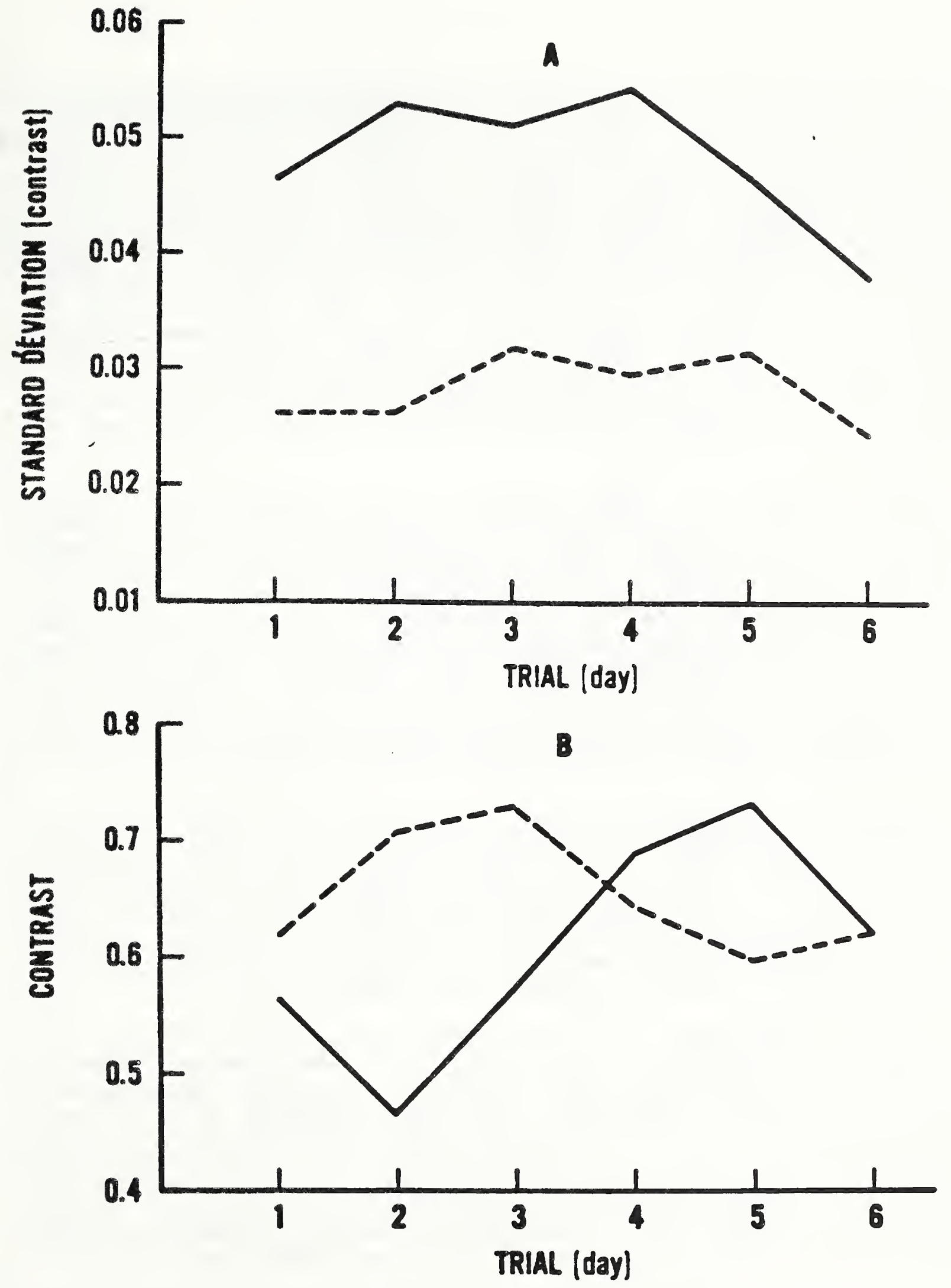

Pigure 12. (a) Standard deviation of matching contrast for target number 1 on six successive days for two subjects (solid line, GY and dashed line, $\mathrm{KL}$ ).

(b) Mean matching contrast for target number 1 on six successive days for two subjects (solid line, GY and dashed line, KL). 
factor is unity when there is no deviation between the experimental and physical contrasts. Figure 11 presents the corrected contrast, which is $\mathrm{C}_{e q}$, for the data presented in figure 9. The correction factor, $C_{r} / C_{r t}$, is less than unity (0.957) for $\mathrm{KL}$ and greater than unity (1.009) for GY and was derived from quantities shown in figure 7. The correction factor narrows the difference between the two subjects, but there still appears to be a consistent difference. The merits of the calibration or correction procedures to minimize between subject differences should be investigated further. The results with the 5-bar as the test sample indicate what appears to be a practice effect between trials 1 and 2. See figure 8 . Except for subject GY, for all other subjects trial 1 was the first conspicuity matching made using this meter. There is no consistent decrease in variability between trials 2 and 3 indicating that practice effects occurred during the first trial or practice may not be an important consideration in matching precision. The decrease in variability from day 1 to day 2 may have been due to unfamiliarity with the meter.

Data were obtained for target number 1 on six different days and are presented in figure $12 \mathrm{~A}$ as standard deviation, for two subjects. Although the days are not consecutive, they are in chronological order. The standard deviation does not appear to change systematically from trial one to trial six. Once a conspicuity criterion is established for a given trial, subjects appear to use this criterion, but may on the next day (trial) use a different criterion and maintain this criterion for the day (trial). Figure 12B gives indications of this changing criterion. The supposition is that practice is not necessary for precision (repeatability) of matches on a given day, but that repeatability between days can be improved by practice and/or training the observer so that he is using the same criterion from day to day, as well as the criterion used by other observers, as discussed earlier.

The conspicuity meter and the procedure described in this paper can be used to evaluate the relative conspicuity of two dimensional tasks as they are seen in the real world. This direct approach avoids the assumptions necessary when task difficulty is assessed indirectly by bringing the task to threshold levels. The threshold technique assumes that the number of just noticeable differences, the ratio of physical contrast to threshold contrast, is a valid measure of suprathreshold task difficulty. Experiments conducted at suprathreshold levels do not support this assumption [3].

It must be emphasized that this methodology primarily evaluates the performance of physiological contributions rather than processed information which is heavily dependent on past experience or learning. For example, a task with an unusual alphanumeric font may be supposed to be difficult because the strokes are too narrow, too closely spaced, or the letters are too broad or narrow, etc.; i.e., variables that make it difficult because of limitations of the physiology of the visual system. On the other hand, the unusual font may be difficult to identify because it bears limited resemblance to common fonts. Presumably, an obscure Old English or Black Letter type face might have high conspicuity, despite being hard to read. 
The apparatus and procedure described in this paper can be used to evaluate the relative "goodness of seeing" of typical two-dimensional office tasks. In order to minimize differences in the absolute contrast values between evaluators, the concept of observer calibration should be investigated. Repeatability of matches by an individual observer does not increase appreciably with practice, although agreement between observers and for a given observer on different days may be increased by training to a common criterion. 
5. REFERENCES

1. Kaufman, J. (ed), IES Lighting Handbook, Illuminating Engineering Society of North America, New York, NY, 1981.

2. International Commission on Illumination (CIE), A Unified Framework of Methods for Evaluating Visual Performance Aspects of Lighting, CIE Publication No. 19 (TC 3.1), Bureau Central 4, Ave Du Recteur Poincare, 75 Paris 16, 1972.

3. Yonemura, G. T., Criteria for Recommending Lighting Levels, Lighting Research and Technology 13, 113-129, 1981. 
NBS-114A (REV. 2-80)

U.S. DEPT. OF COMM.

BIBLIOGRAPHIC DATA

SHEET (See instructions)

1. PUBLICATION OR REPORT NO.

NISTIR $\quad 89-4226$

2. Performing Organ. Report Nod 3. Publication Date

4. TITLE ANO SUBTITLE

A Suprathreshold Visibility Meter to Directly Assess the Conspicuity of Office Tasks

5. AUTHOR(S)

Gary T. Yonemura and Karen Lister

6. PERFORMING ORGANIZATION (If joint or other than NBS, see instructions)

7. Conerace/Grane No.

NATIONAL BUREAU OF STANDARDS

DEPARTMENT OF COMMERCE

WASHINGTON, D.C. 20234

8. Type of Report \& Period Covered

Einal

9. SPONSORING ORGANIZATION NAME AND COMPLETE ADDRESS (Street, City, Stote, ZIP)

U.S. Department of Energy

through: University of California, Lawrence Berkeley Laboratory

Berkeley, CA 94720 and NBS

10. SUPPLEMENTARY NOTES

Document describes a computer program; SF-185. FIPS Software Summary, is attached.

11. ABSTRACT (A 200-word or less factual summary of most significant information. If document includes o significant bibliography or literature survey. mention it here)

An apparatus and methodology for evaluating the relative difficulty of visibility related office tasks are described. The methodology differs from current evaluation techniques in that tasks are assessed in the laboratory as seen in the real world. The contrast of a reference task (5-bar grating) is varied until the conspicuity (how well the detail stands out from the background) is perceived to be equal to that of the sample task presented simultaneously. Data using typical alphanumeric materials encountered in commercial activities are presented. The investigation indicates that the apparatus and methodology give a good indication of the relative difficulty of real world sample tasks. Procedures for calibrating the task evaluators or the inclusion of a criterion correction factor in order to minimize differences in absolute values between evaluators are recommended.

12. KEY WORDS (Six to twelve entries; alphabetical order; capitalize only proper names; and separate key words by semicolons) Conspicuity, contrast, legibility, office tasks, lighting, lighting requirements, task lighting, task performance, visibility.

13. AVAILABILITY

Unlimited

For Official Distribution. Do Not Release to NTIS

Order From Superintendent of Documents, U.S. Government Printing Office, Washington, D.C. 20402.

X] Order From National Technical Information Service (NTIS), Springfield, VA. 2216।
14. NO. OF PRINTED PAGES

32

15. Price

$\mathrm{AO} 3$ 


